\title{
MEASUREMENT AND PREDICTION OF KARSTIC SPRING FLOW RATES
}

\section{DARIVIANAKIS N. KATSIFARAKIS K.L. ${ }^{*}$ VAFEIADIS $M$.}

Received: $23 / 08 / 2014$

Accepted: 09/01/2014

Available online: 13/03/2015
Division of Hydraulics and Environmental Engineering Dept. of Civil Engineering, Aristotle University of Thessaloniki

GR- 54124 Thessaloniki, Greece

*to whom all correspondence should be addressed: e-mail: klkats@civil.auth.gr

\section{ABSTRACT}

This paper deals with prediction of the response of karstic springs by means of artificial neural networks (ANNs). A feed-forward back propagation ANN with three layers has been developed, to predict flow rates of two karstic springs, located at Rouvas area, Crete, Greece, using rainfall data as input. While the number of neurons of the input and output layers was determined by choice of data and desired output respectively, the number of neurons of the hidden layer was decided by means of numerous tests. Data used in ANN training and testing include daily and monthly precipitation depths (from September, 2006 to December, 2010) and measured flow rates of the two springs (from April, 2007 to December, 2010). Results show that the trained artificial neural network performed well, although flow rate measurements were not very regular. Moreover, the possibility of estimating the flow rate of one spring, based on measurements of the other has been investigated. Again the ANN gave satisfactory results. All spring flow rate and rainfall measurements are presented as an appendix, to facilitate further scientific research in the area of ANN application to water resources management.

Keywords: karstic aquifer; karstic spring; artificial neural network; flow rate measurement

\section{Introduction}

Karstic aquifers are very important water resources for many areas of the world and it is estimated that 20 to $25 \%$ of the global population depends on them (Ford and Williams, 2007). Their efficient management is a very challenging task. The first problem that arises is proper flow simulation; application of the empirical Darcy law, used for flows through porous media, may not yield satisfactory results in karstic aquifers, due to the size and structure of void spaces, serving as water conduits.

When development of turbulent flow is anticipated, use of the Forchheimer formula leads, in principle, to more accurate results. This formula reads:

$$
\text { gradh }=c V+d V^{2}
$$

where $\mathrm{h}$ is the hydraulic head and $\mathrm{V}$ the Darcy velocity. Its combination with continuity equation is not that efficient, from the computational point of view, and for this reason its application is rather restricted (e.g. Moutsopoulos and Tsihrintzis, 2005; Mathias and Todman, 2010).

Moreover, in karstic (and fractured) aquifers different families of void spaces may exist, due to karstification and primary rock permeability. In such cases, dual porosity models might seem more appropriate. They have the drawback, though, of introducing additional flow parameters that are not 
easily defined (i.e. hydraulic conductivity for each medium and a constant for mass exchange between the two).

When rock karstification is intense, water actually flows through a network of natural conduits. In such cases models used to describe flows in pipe networks are more suitable. But knowledge of the network geometry is in most cases restricted, therefore some kind of macroscopic approach cannot be avoided (e.g. Jeannin, 2001). Moreover, in many cases flow due to the primary porosity of the host rock cannot be neglected (e.g. Liedl et al., 2003). In such cases, combination of different flow models can be very useful (e.g. Rooij et al., 2013). Use of Navier-Stokes equations has also been examined (Masciopinto and Palmiotta, 2013).

The last few years karstic aquifers have been simulated either as systems of reservoirs (e.g. Fleury et al., 2009) or by means of artificial neural networks (ANNs), as discussed in the following section. In our study we have used an ANN to "simulate" a karstic aquifer, feeding two springs. The karstic system is located at the Rouvas area of the island of Crete, Greece, shown in Figure 1. Actually, our purpose was to forecast the spring flow rates, based on local rainfall data. The reason for using ANN is explained in the following section.

\section{Artificial neural networks and their usefulness}

Artificial Neural Networks (ANNs) are based on the idea that certain properties of biological neurons can be used for the creation of a simplified "brain", which imitates, to an extent, the learning and computational capacity of human brain. They are essentially grids of processing units, called neurons, which are arranged in layers (input, hidden and output layers). Each neuron produces an output value, based on input information received from other neurons. Each item of input information is weighted by a coefficient, called synaptic weight, which expresses the importance attributed to the particular source of input information. Neuron output depends on the weighted sum of inputs and a preselected activation function.

Approach to a problem by means of ANNs does not aim at mathematical description of natural phenomena, but at obtaining quantitative results for given data sets, based on "experience" from similar known cases. So, ANNs could be particularly useful when a) mathematical simulation of the physical phenomena is either impossible or too complicated and b) Parameters necessary for mathematical simulation (e.g. hydraulic conductivity, storativity) cannot be defined with acceptable accuracy. These situations arise quite often with karstic aquifers, rendering use of ANNs attractive. Moreover, surrogate models, such as artificial neural networks, are used quite often in conjunction with evolutionary optimization techniques, such as genetic algorithms, in order to reduce total computational volume, even when porous aquifers are involved (e.g. Nikolos et al., 2008; Sreekanth and Datta, 2010). Combinations of ANNs with deterministic models have also been used (e.g. Lallahem and Mania, 2003; Jain and Srinivasulu, 2004; Chen and Adams, 2006).

ANNs have been already used extensively in water resources management problems (e.g. Kralisch et al., 2003), modeling of rainfall-runoff relationship (e.g. Baratti et al., 2003; Rajurkar et al., 2004; Pan et al., 2007), flood forecasting (e,g. Lekkas et al., 2004), groundwater level forecasting (e.g. Daliakopoulos et al., 2005; Trichakis et al., 2011), groundwater pollution prediction (e.g. Sahoo et al., 2005), determination of aquifer parameters (e.g. Zio, 1997; Samani et al., 2007), prediction of reservoir inflow and level (e.g. Coulibaly et al., 2005; Chang and Chang, 2006), etc. Regarding prediction of karstic spring discharge, encouraging results have been obtained, at least when there are abundant field data (e.g. Kurtulus and Razack, 2007; Hu et al., 2008).

The most difficult stage in ANN application is selection of the most suitable structure for the examined problem, including number of layers, number of neurons of each layer, activation functions and connection weights. Experience from similar applications can serve as a guide, but the final choice is definitely case-specific. 
Despite their usefulness, ANNs (or other surrogate models) may introduce some additional uncertainty. In such cases, use of ensembles of surrogate models has been recommended (Sreekanth and Datta, 2011).

\section{The study area}

Karstic systems are rather common in Greece (e.g. Novel et al., 2007; Tsakiris et al., 2009). As mentioned in section 1, this paper focuses on two karstic springs appearing at a distance of $800 \mathrm{~m}$ from each other, in the area of Gergeri (ex-Rouvas municipality), Crete, which is shown in Fig. 1. The two springs are called "Mai Vryssi" and "Pera Vryssi". They are found at an elevation of $500 \mathrm{~m}$ asl approximately, while the average elevation of the area, which feeds the karstic system, is $950 \mathrm{~m}$ asl. A number of other springs appear in the same area, some of them in rough terrain.

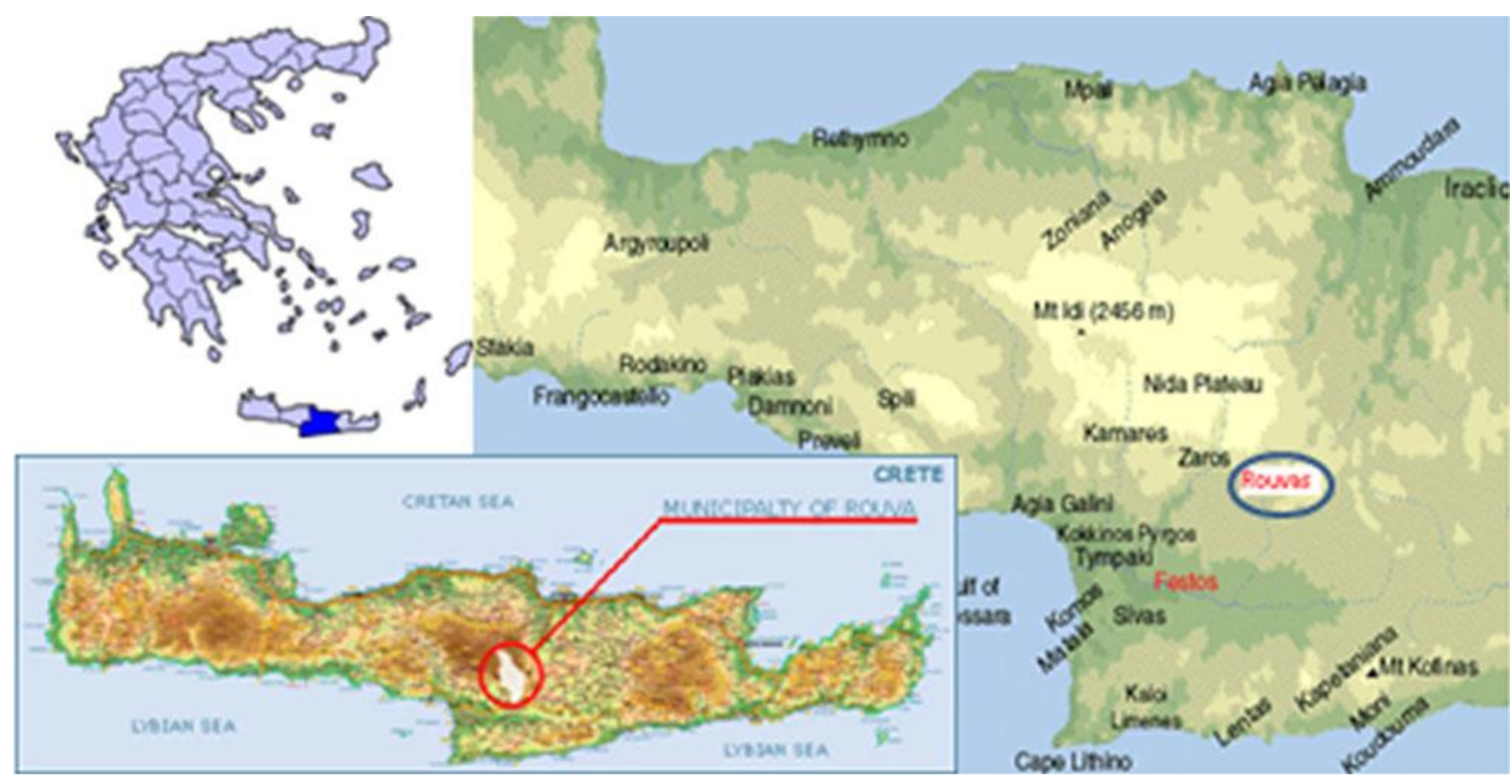

Figure 1. Study area (Paleologos et al., 2013)

\subsection{Field data}

To train and test the ANN, field data have been used, namely local daily precipitation and flow rates of the two karstic springs. These data cover a period larger than 3 years (daily rainfall from September, 2006 to December, 2010 and measured flow rates of the two springs from April 2007 to December 2010) and they have been collected by N. Darivianakis, mostly in the framework of his Ph.D. Thesis (Darivianakis, 2011).

A complete and reliable set of rainfall data (rainfall depth per day) was available from a rain gauge which is installed at the vicinity of Pera Vryssi, namely at a very suitable location for the purpose of this study.

The flow rates of the two springs have been measured in a very simple way, by means of a chronometer (accurate to one hundredth of a second) and a volumetric vessel. That vessel had a total volume of 18 It. Each spring has two outlets. For each outlet, the time to fill the vessel up to the indication of 15 litres was counted three times. Then, the mean was used to calculate the flow rate of each outlet. Finally, the flow rate values of the two outlets were added to each other. While measured flow rate values are reliable, the measurement schedule has been rather irregular, rendering ANN application more challenging.

A table including all field data appears in Appendix, in order to facilitate testing of other ANNs. Dates of rain and/or spring flow rate measurements are shown in the first column. Precipitation depths (in $\mathrm{mm}$ ) appear in the second column, while the third and fourth include flow rates of Mai Vryssi and Pera Vryssi, respectively (in Lit s ${ }^{-1}$ ). 


\section{The investigated problems}

Three problems have been investigated:

a. Simultaneous forecast of the flow rates of the two springs, based on precipitation data.

b. Forecast of the flow rate separately for each spring, based on precipitation data.

c. Forecast of the flow rate of one spring, based on the flow rate of the other and on precipitation data.

\subsection{Selection of basic ANN features}

As mentioned in section 2, selection of ANN is a case-specific task. We have opted for feed-forward, backpropagation ANN, based on literature for similar problems.

Back-propagation ANNs (e.g. Fausett, 1994) use supervised learning algorithms, namely they are provided both with input patterns and desired output patterns. After producing their own output, the ANNs calculate the discrepancy between estimated and expected output values, and adjust the synaptic weights in order to minimize it. The Root Mean Squared Error (RMSE) is used as discrepancy measure. Commonly used back propagation networks minimize RMSE by means of a gradient descent technique. In this work, we have used the Quickprop algorithm, which has been proposed by Fahlman (1988) and encompasses training speeding techniques. This choice was based mainly on previous positive experience of the authors with this algorithm, in cases with restricted field data (Fytianos and Katsifarakis, 2013). Moreover, the sigmoid function is used as activation function.

We have restricted our study to ANNs with three layers, namely with one hidden layer only, based again on literature for similar problems (e.g. Lallahem et al., 2005; Kurtulus and Razack, 2007; Hu et al., 2008) and on our anticipation (based on the geological features of the karstic area) that additional complexity, introduced by more hidden layers, will not be necessary.

Selection of a suitable ANN structure for a particular problem may not be unique. Using the larger part of the aforementioned rainfall and spring flow data Paleologos et al., (2013) have come up with different ANN structures.

\subsection{Selection of input data}

To complete the construction of ANN for each of the aforementioned problems, we had to decide on: a) The combination of input data (and consequently the number of the neurons of the input layer) and b) the number of neurons of the hidden layer.

Decision on the input data was based on comparative inspection of precipitation and spring flow rate data and on soft information on the behavior of the two springs, provided by residents of the area, who call the "Pera Vryssi" spring short (namely responding earlier to rainfall and for a shorter period of time). Our aim was to arrive at practically useful predictions, namely to estimate spring flow rates at least few days in advance. Moreover, we aimed at checking whether a gross prediction, based on rainfall data of previous months, was meaningful. Having the above in mind, we conducted trials, using: a) Rainfall depths of the $5^{\text {th }}$ up to the $16^{\text {th }}$ day prior to the flow rate measurement date and b) Mean precipitation of the first up to the sixth month prior to the flow rate measurement date. After evaluation of these initial trials, we decided to include some, or all, of the following data:

1. Rainfall depth of the $5^{\text {th }}$ day prior to the flow rate measurement date

2. Rainfall depth of the $6^{\text {th }}$ day prior to the flow rate measurement date

3. Rainfall depth of the $7^{\text {th }}$ day prior to the flow rate measurement date

4. Rainfall depth of the $13^{\text {th }}$ day prior to the flow rate measurement date

5. Rainfall depth of the $14^{\text {th }}$ day prior to the flow rate measurement date

6. Rainfall depth of the $15^{\text {th }}$ day prior to the flow rate measurement date

7. Mean precipitation of the month prior to the flow rate measurement date 
8. Mean precipitation of the $2^{\text {nd }}$ month prior to the flow rate measurement date

9. Mean precipitation of the $3^{\text {rd }}$ month prior to the flow rate measurement date

10. Mean precipitation of the $6^{\text {th }}$ month prior to the flow rate measurement date.

Decision on the number of the neurons of the hidden layer was based on extensive trials. An outline of these trials appears in the next section, together with the results.

\subsection{Trials and results}

The first task was to construct an ANN that would forecast simultaneously the flow rate of both springs. Then, the output layer had two neurons, one for each flow rate. We divided the field data in two sets, one for training and one for testing, since their number is rather restricted (Hu et al., 2008; Jain et al., 2004). For training we used the 171 spring flow measurements of the first year, namely from April 16, 2007 to April 15 2008, during which measurements were more regular. The remaining 91 have been used for testing.

We have conducted a large number of trials, regarding both the input data and the number of neurons of the hidden layer. The best results were achieved when the rainfall depth of the $5^{\text {th }}, 6^{\text {th }}, 7^{\text {th }}, 13^{\text {th }}, 14^{\text {th }}$ and $15^{\text {th }}$ day, together with the mean precipitation of the $1^{\text {st }}, 2^{\text {nd }}$ and $3^{\text {rd }}$ month prior to the flow rate measurement date were used. For this input combination, the dependence of the RMSE on the number of neurons of the hidden layer $\mathrm{N}_{\mathrm{h}}$ is shown in Table 1.

Table 1. RMSE versus $\mathrm{N}_{\mathrm{h}}$ (forecast of flow rate of both springs)

\begin{tabular}{cccc}
\hline $\mathrm{N}_{\mathrm{h}}$ & \multicolumn{3}{c}{ RMSE $\left(\right.$ Lit s $\left.{ }^{-1}\right)$} \\
\cline { 2 - 4 } & Mai Vryssi & Pera Vryssi & Mean \\
\hline 1 & 0.875 & 1.243 & 1.059 \\
\hline 2 & 0.786 & 1.081 & 0.933 \\
\hline 3 & 0.804 & 1.002 & 0.903 \\
\hline 4 & 0.830 & 1.192 & 1.011 \\
\hline 5 & 0.838 & 1.036 & 0.937 \\
\hline 10 & 0.797 & 1.060 & 0.929 \\
\hline 12 & 0.829 & 0.966 & 0.898 \\
\hline 14 & 0.816 & 1.010 & 0.913 \\
\hline 18 & 0.815 & 0.981 & 0.898 \\
\hline
\end{tabular}

As shown in Table 1 RMSE was always larger for Pera Vryssi. It seems that ANN tends to approximate better the larger of the 2 flow rates. Moreover, it attained its minimum value for 12 and 2 neurons for Pera Vryssi and Mai Vryssi, respectively. This somehow affirmed information from local residents, that the two springs exhibit different behavior.

Then we tried to develop an ANN separately for each spring. For Mai Vryssi best results (RMSE $=0.737$ Lit $\left.\mathrm{s}^{-1}\right)$ were achieved with the same input data and 4 neurons in the hidden layer. For Pera Vryssi best results (RMSE $=0.522$ Lit s$^{-1}$ ) were achieved with 10 neurons in the hidden layer and all of the input data (namely when the mean precipitation of the $6^{\text {th }}$ month prior to the date of measurement was added, too). Again, best results for May Vryssi have been achieved with substantially fewer neurons in the hidden layer, compared to Pera Vryssi. While ANNs are black box models, one could try to relate their structure to physical processes (e.g. Govindaraju, 2000; Jain et al., 2004). In the case of Rouvas springs the aforementioned difference in the number of hidden layer neurons could be partially explained in the following way: As May Vryssi is fed by a comparatively larger area, local inhomogeneities are partially smoothed.

Calculated versus measured flow rates for Pera Vryssi appear in Fig. 2. Flow rate values (in Lit s $\mathrm{s}^{-1}$ ) appear on the $y$-axis, while the measurement number (starting from April 16, 2008) on the $x$-axis. It can be seen that the predicted values are generally smaller than the measured ones, but they follow a similar pattern. Visual inspection in this case verifies that the ANN performance is good. 


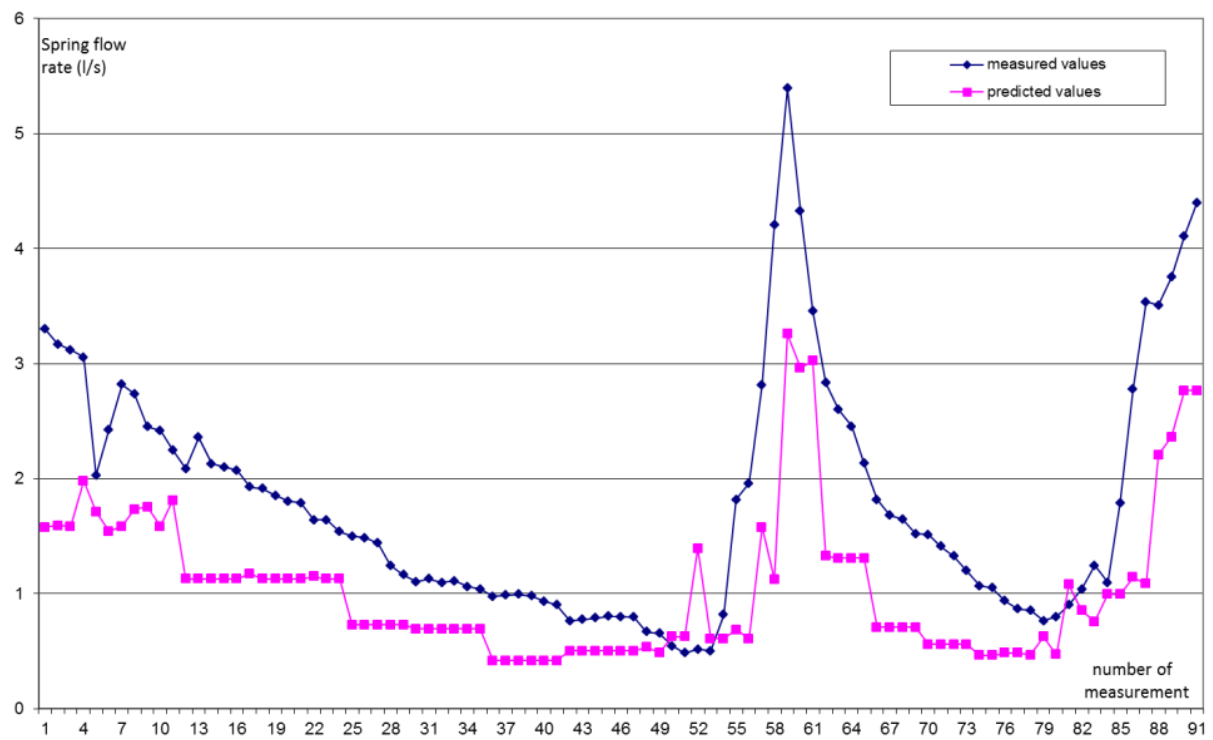

Figure 2. Calculated versus measured flow rates of Pera Vryssi

Moreover, since both springs have perennial flow, we checked whether some medium-term forecast is possible, using combinations of the aforementioned mean monthly precipitation values as input. Use of the mean precipitation of the first, second and third month prior to the date of measurement gave some acceptable results, namely RMSE $=0.746$ Lit s$^{-1}$ with 9 neurons in the hidden layer for Mai Vryssi and RMSE $=1.044$ Lit s$^{-1}$ with 6 neurons in the hidden layer for Pera Vryssi.

Then we checked whether we could use seasonal data for ANN training. This approach failed for Pera Vryssi but gave very good results for Mai Vryssi with regard to the RMSE criterion), although available data for training and testing are few, namely 31 for the training set (from spring, 2007) and 48 for the test set). With 12 neurons in the hidden layer and the complete set of input data RMSE is equal to 0.406 Lit $\mathrm{s}^{-1}$. Calculated versus measured flow rates for the season of spring appear in Fig. 3. A rather large discrepancy appears in measurements 38 to 46 , which correspond to spring 2009. Data inspection shows that rain was much heavier in early 2009 than in 2007. The aforementioned discrepancy could be attributed then to the fact that data for the training period come from one year's spring season only.

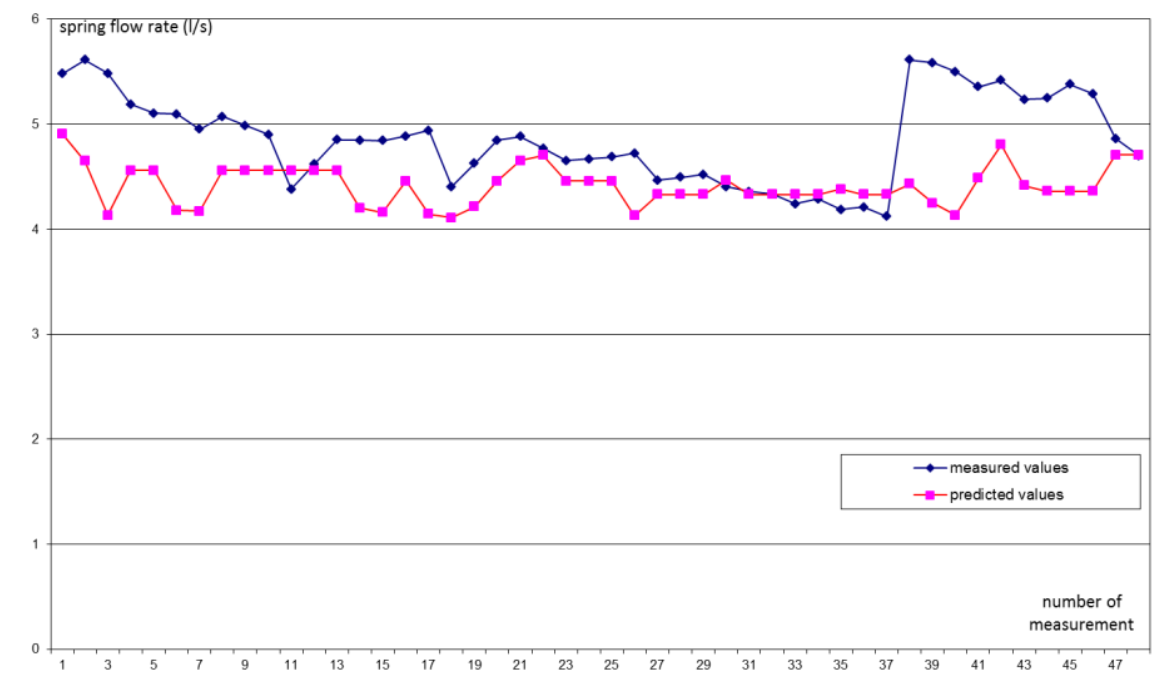

Figure 3. Mai Vryssi: Calculated versus measured flow rates for the season of spring 


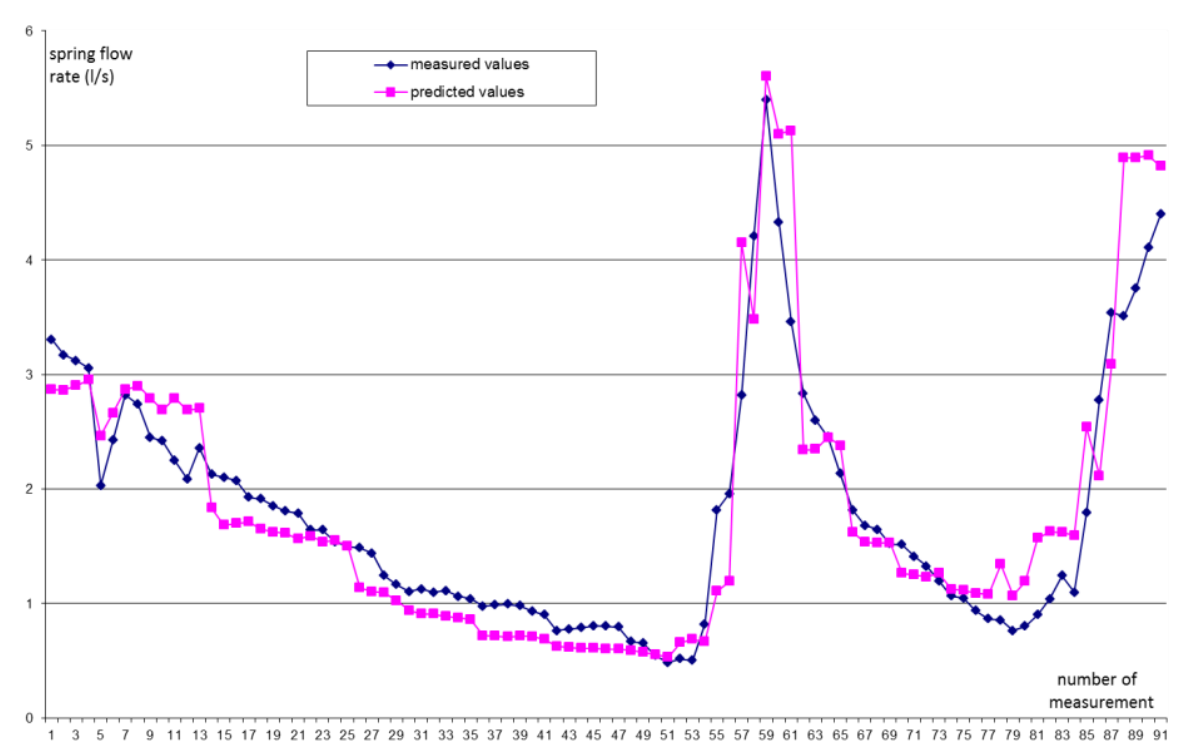

Figure 4. Calculated versus measured flow rates of Pera Vryssi (based on flow rates of Mai Vryssi and precipitation data)

Finally, we checked whether it was possible to forecast flow rate of one spring based on rainfall data and the flow rate of the other. This can be useful in practice, if access to certain springs is difficult. Despite our reservations, due to the different response of the two springs, we have achieved good results in forecasting the flow rate of Pera Vryssi, using as input the mean precipitation of the first, second, third and sixth month prior to the date of measurement, together with the flow rate of Mai Vryssi during the same day. As shown in Fig.4, calculated flow rate values follow the same pattern as the measured ones. The respective RMSE value is $0.447 \mathrm{Lit} \mathrm{s}^{-1}$ and has been achieved with 5 neurons in the hidden layer.

\section{Conclusions}

In our work we have tried to check ANN usefulness in providing predictions of karstic spring flow rates with restricted field data. For this reason, we have not used interpolation to artificially enrich the flow rate measurement set. Moreover, we have tried to get approximate, but comparatively early predictions, although karstic springs may respond rather quickly to rain events. Finally we have taken into account and we have evaluated soft information on spring behavior. The results that we have got led us to the following conclusions:

1) Artificial neural networks can serve for approximate prediction of karstic spring flow rates, even if the training data set is short. Moreover, they can offer useful results, even if flow rate measurements are not very regular.

2) Gross medium-term (e.g. one month) forecast could be achieved, at least for some perennial springs, as those studied in our paper.

2) Extensive trials are needed to achieve good results. In our paper we have presented a rather small part of the total volume of trials.

3) Different ANN structures can lead to comparable results. We have come to this conclusion, comparing our results with those presented in the literature, based on almost the same field data.

4) Visual inspection of calculated versus measured flow rate diagrams could be combined with the RMSE criterion, in order to achieve better evaluation of the ANN results.

5) Soft information on the behavior of springs could be useful in ANN construction. As an example, we have found out that the different behavior of the two springs, mentioned by residents of the area, was "verified" by the different structure of the ANNs that best fit the two springs. 


\section{References}

Baratti R., Cannas B., Fanni A., Pintus M., Sech G.M. and Toreno N. (2003), River flow forecast for reservoir management through neural networks, Neurocomputing, 55, $421-437$.

Chang F.-J. and Chang Y.-T. (2006), Adaptive neuro-fuzzy inference system for prediction of water level in reservoir, Adv. Water Resour., 29, 1-10.

Chen J. and Adams B.J. (2006), Integration of artificial neural networks with conceptual models in rainfall-runoff modeling, J. Hydrol., 318, 232-249.

Coulibaly P., Haché M., Fortin V. and Bobée B. (2005), Improving Daily Reservoir Inflow Forecasts with Model Combination, J. Hydrol. Eng., 10(2), 91-99.

Daliakopoulos I.N., Coulibaly P. and Tsanis I.K. (2005), Groundwater level forecasting using artificial neural networks, J. of Hydrol., 309, 229-240.

Darivianakis N. (2011), Prediction of karstic aquifer response by means of artificial neural networks, Ph.D. Thesis, Dept. of Civil Engineering, Aristotle University of Thessaloniki, Greece (in Greek).

de Rooij R., Perrochet P. and Graham W. (2013), From rainfall to spring discharge: Coupling conduit flow, subsurface matrix flow and surface flow in karst systems using a discrete-continuum model, Advances Water Resour., 61, 29-41.

Fahlman S.E. (1988), An empirical study of learning speed in back-propagation networks, Computer Science Dept., Paper 1800.

Fausett L. (1994), Fundamentals of Neural Networks, Prentice Hall, Englewood Cliffs, NJ.

Fleury P., Ladouche B., Conroux Y., Jourde H. and Dőrfliger N. (2009), Modelling the hydrologic function of a karst aquifer under active water management, J. Hydrol., 365, 235-243.

Ford D. and Williams P. (2007), Karst hydrogeology and geomorphology. Wiley.

Fytianos G. and Katsifarakis K.L. (2013), Correlation and prediction of chemical parameters in ground water of the municipality of Thermi using SPSS, G.I.S. and artificial neural networks, In: e-proceedings of CEST 2013, Athens, September 2013.

Govindaraju R.S. (2000), Artificial Neural Networks in Hydrology. II: Hydrologic Applications, J. Hydrol. Eng., 5(2), 124-137

Hu C., Hao Y., Yeh T.-C. J., Pang B. and Wu Z. (2008), Simulation of spring flows from a karst aquifer with an artificial neural network, Hydrol. Process, 22, 596-604. doi: 10.1002/hyp.6625.

Jain A. and Srinivasulu S. (2004), Development of effective and efficient rainfall-runoff models using integration of deterministic, real-coded GA, and ANN techniques, Water Resour. Res., 40(4), doi:10.1029/2003WR002355.

Jain A., Sudheer K.P. and Srinivasulu S. (2004), Identification of physical processes inherent in artificial neural network rainfall runoff models, Hydrol. Process., 18, 571-581.

Jeannin P.-Y. (2001), Modeling flow in phreatic and epiphreatic karst conduits in the Hölloch cave (Muotatal, Switzarland), Water Resour. Res., 37, 191-200.

Kralisch S., Fink M., Flugel W.A. and Beckstein C. (2003), A neural network approach for the optimization of watershed management, Environ. Model Softw., 18, 815-823.

Kurtulus B. and Razack M. (2007), Evaluation of the ability of an artificial neural network model to simulate the inputoutput responses of a large karstic aquifer: the La Rochefoucauld aquifer (Charente, France), Hydrogeol. J., 15(2), 241-254.

Lallahem S. and Mania J. (2003) Evaluation and forecasting of daily groundwater outflow in a small chalky watershed, Hydrol. Process., 17, 1561-1577, doi: 10.1002/hyp.1199.

Lallahem S., Mania J., Hani A. and Najjar Y. (2005), On the use of neural networks to evaluate groundwater levels in fractured media, J. Hydrol., 307, 92-111.

Lekkas D.F., Onof C., Lee M.J. and Baltas E.A. (2004), Application of artificial neural networks for flood forecasting, Global NEST Journal, 6(3), 205-211.

Liedl R., Sauter M., Húckinghaus D., Clemens T. and Teutsch G. (2003), Simulation of the development of karst aquifers using a coupled continuum pipe flow model, Water Resour. Res., 39(3), 1057, doi:10.1029/2001WR001206, 3. 
Masciopinto C. and Palmiotta D. (2013) Relevance of solutions to the Navier-Stokes equations for explaining groundwater flow in fractured karst aquifers, Water Resour. Res., 49, 3148-3164, doi:10.1002/wrcr.20279.

Mathias S.A. and Todman L.C. (2010) Step-drawdown tests and the Forchheimer equation, Water Resour. Res., 46, doi:10.1029/2009WR008635.

Moutsopoulos K.N. and Tsihrintzis V.A. (2005), Approximate analytical solutions of the Forchheimer equation, J. Hydrol., 309, 93-103.

Nikolos I.K., Stergiadi M., Papadopoulou M.P. and Karatzas G.P. (2008), Artificial neural networks as an alternative approach to groundwater numerical modelling and environmental design, Hydrol. Process., 22, 3337-3348.

Novel J.P., Dimadi A., Zervopoulou A. and Bakalowicz M. (2007) The Aggitis karst system, Eastern Macedonia, Greece: Hydrologic functioning and development of the karst structure, J. Hydrol., 334, 477- 492.

Paleologos E.K., Skitzi I., Katsifarakis K. and Darivianakis N. (2013) Neural network simulation of spring flow in karst environments, J. Stoch. Environ. Res. Risk Assess. (SERRA), 27(8), 1829-1837.

Pan T.-Y., Wang R.-Y. and Lai J.-S. (2007) A deterministic linearized recurrent neural network for recognizing the transition of rainfall-runoff processes, Advances Water Resour., 30, 1797-1814.

Rajurkar M.P., Kothyari U.C. and Chaube U.C. (2004), Modeling of the daily rainfall-runoff relationship with artificial neural network, J. Hydrol., 285, 96-113.

Sahoo G.B., Ray C. and Wade H.F. (2005), Pesticide prediction in ground water in North Carolina domestic wells using artificial neural networks, Ecol. Model., 183, 29-46.

Samani N., Gohari-Moghadam M. and Safavi A.A. (2007), A simple neural network model for the determination of aquifer parameters, J. Hydrol., 340, 1-11.

Sreekanth J. and Datta B. (2010), Multi-objective management of saltwater intrusion in coastal aquifers using genetic programming and modular neural network based surrogate models, J. Hydrol., 393(3-4), 245 - 256.

Sreekanth J. and Datta B. (2011), Coupled simulation-optimization model for coastal aquifer management using genetic programming-based ensemble surrogate models and multiple-realization optimization, Water Resour. Res., 47, doi: 10.1029/2010WR009683.

Trichakis I., Nikolos I. and Karatzas G.P (2011), Artificial Neural Network (ANN) Based Modeling for Karstic Groundwater Level Simulation, Water Resour. Manag., 25(4), 1143-1152.

Tsakiris G., Spiliotis M., Paritsis S. and Alexakis D. (2009), Assessing the water potential of karstic saline springs by applying a fuzzy approach: The case of Almyros (Heraklion, Crete), Desalination, 237, 54-64.

Zio E. (1997), Approaching the inverse problem of parameter estimation in groundwater models by means of artificial neural networks, Prog. Nucl. Energy, 31(3), 301-315.

\section{Appendix: Precipitation and spring flow rate data}

\begin{tabular}{c|c|c|c|c|c|c|c}
$\begin{array}{c}\text { date } \\
\mathrm{dd} / \mathrm{mo} / \mathrm{yr}\end{array}$ & $\begin{array}{c}\text { Precipi- } \\
\text { tation } \\
(\mathrm{mm})\end{array}$ & $\begin{array}{c}\text { Mai Vryssi } \\
\text { flowrate } \\
\left(\text { Lit s}^{-1}\right)\end{array}$ & $\begin{array}{c}\text { Pera Vryssi } \\
\text { flowrate } \\
\left(\text { Lit s}^{-1}\right)\end{array}$ & $\begin{array}{c}\text { date } \\
\text { dd/mo/yr }\end{array}$ & $\begin{array}{c}\text { Precipi- } \\
\text { tation } \\
(\mathrm{mm})\end{array}$ & $\begin{array}{c}\text { Mai Vryssi } \\
\text { flowrate } \\
\left(\text { Lit s}^{-1}\right)\end{array}$ & $\begin{array}{c}\text { Pera Vryssi } \\
\text { flowrate } \\
\left(\text { Lit s}^{-1}\right)\end{array}$ \\
\hline $20 / 09 / 2006$ & 13,00 & & & $02 / 05 / 2008$ & & 4,725 & 2,359 \\
\hline $23 / 09 / 2006$ & 2,50 & & & $07 / 05 / 2008$ & & 4,468 & 2,128 \\
\hline $10 / 10 / 2006$ & 9,50 & & & $08 / 05 / 2008$ & & 4,495 & 2,101 \\
\hline $11 / 10 / 2006$ & 12,00 & & & $09 / 05 / 2008$ & & 4,522 & 2,074 \\
\hline $12 / 10 / 2006$ & 1,70 & & & $10 / 05 / 2008$ & & & \\
\hline $13 / 10 / 2006$ & 5,00 & & & $11 / 05 / 2008$ & 4,10 & & \\
\hline $15 / 10 / 2006$ & 1,50 & & & $13 / 05 / 2008$ & & 4,403 & 1,928 \\
\hline $17 / 10 / 2006$ & 68,00 & & & $14 / 05 / 2008$ & & 4,360 & 1,912 \\
\hline $18 / 10 / 2006$ & 13,00 & & & $19 / 05 / 2008$ & & 4,336 & 1,853 \\
\hline $01 / 11 / 2006$ & 25,00 & & & $20 / 05 / 2008$ & & 4,243 & 1,805 \\
\hline $02 / 11 / 2006$ & 15,00 & & & $22 / 05 / 2008$ & & 4,287 & 1,788 \\
\hline $03 / 11 / 2006$ & 130,00 & & & $26 / 05 / 2008$ & & 4,188 & 1,641 \\
\hline $05 / 11 / 2006$ & 4,00 & & & $27 / 05 / 2008$ & & 4,211 & 1,642 \\
\hline $12 / 11 / 2006$ & 32,50 & & & $30 / 05 / 2008$ & & 4,121 & 1,538 \\
\hline $14 / 11 / 2006$ & 106,00 & & & $03 / 06 / 2008$ & & 4,052 & 1,499 \\
\hline $23 / 11 / 2006$ & 14,00 & & & $09 / 06 / 2008$ & & 3,961 & 1,485
\end{tabular}




\begin{tabular}{|c|c|c|c|c|c|c|c|}
\hline $24 / 11 / 2006$ & 15,50 & & & $11 / 06 / 2008$ & & 3,925 & 1,439 \\
\hline $27 / 11 / 2006$ & 0,70 & & & $24 / 06 / 2008$ & & 3,716 & 1,244 \\
\hline $06 / 12 / 2006$ & 2,50 & & & $02 / 07 / 2008$ & & 3,643 & 1,164 \\
\hline $13 / 12 / 2006$ & 9,00 & & & $08 / 07 / 2008$ & & 3,493 & 1,105 \\
\hline $19 / 12 / 2006$ & 4,50 & & & $09 / 07 / 2008$ & & 3,491 & 1,127 \\
\hline $27 / 12 / 2006$ & 3,50 & & & $14 / 07 / 2008$ & & 3,415 & 1,098 \\
\hline 03/01/2007 & 22,00 & & & $18 / 07 / 2008$ & & 3,401 & 1,112 \\
\hline $05 / 01 / 2007$ & 3,00 & & & $23 / 07 / 2008$ & & 3,331 & 1,061 \\
\hline $13 / 01 / 2007$ & 7,50 & & & $28 / 07 / 2008$ & & 3,255 & 1,039 \\
\hline $14 / 01 / 2007$ & 26,00 & & & $01 / 08 / 2008$ & & 3,231 & 0,977 \\
\hline $20 / 01 / 2007$ & 1,00 & & & $04 / 08 / 2008$ & & 3,224 & 0,988 \\
\hline $03 / 02 / 2007$ & 7,00 & & & $06 / 08 / 2008$ & & 3,164 & 0,993 \\
\hline $05 / 02 / 2007$ & 12,50 & & & $07 / 08 / 2008$ & & 3,216 & 0,979 \\
\hline $06 / 02 / 2007$ & 9,00 & & & $11 / 08 / 2008$ & & 3,198 & 0,935 \\
\hline $12 / 02 / 2007$ & 32,50 & & & $9 / 09 / 2008$ & & 2,801 & 0,764 \\
\hline $15 / 02 / 2007$ & 3,00 & & & $15 / 09 / 2008$ & & 2,761 & 0,776 \\
\hline $17 / 02 / 2007$ & 24,00 & & & $21 / 09 / 2008$ & 16,00 & & \\
\hline $18 / 02 / 2007$ & 22,50 & & & $22 / 09 / 2008$ & & 2,712 & 0,788 \\
\hline $25 / 02 / 2007$ & 36,00 & & & $23 / 09 / 2008$ & 4,00 & 2,705 & 0,804 \\
\hline $28 / 02 / 2007$ & 14,50 & & & $24 / 09 / 2008$ & & 2,672 & 0,801 \\
\hline $10 / 03 / 2007$ & 10,00 & & & $25 / 09 / 2008$ & & 2,669 & 0,801 \\
\hline $13 / 03 / 2007$ & 14,00 & & & $29 / 09 / 2008$ & 5,00 & 2,618 & 0,667 \\
\hline $21 / 03 / 2007$ & 20,50 & & & $03 / 10 / 2008$ & 1,00 & & \\
\hline $22 / 03 / 2007$ & 13,00 & & & $12 / 10 / 2008$ & 3,50 & & \\
\hline $24 / 03 / 2007$ & 6,50 & & & $15 / 10 / 2008$ & 3,00 & & \\
\hline $25 / 03 / 2007$ & 11,00 & & & $21 / 10 / 2008$ & & 2,411 & 1,250 \\
\hline $11 / 04 / 2007$ & 1,20 & & & $04 / 11 / 2008$ & & 2,353 & 0,546 \\
\hline $16 / 04 / 2007$ & & 3,397 & 2,197 & $17 / 11 / 2008$ & & 2,230 & 0,484 \\
\hline $17 / 04 / 2007$ & 6,00 & 3,542 & 2,259 & $18 / 11 / 2008$ & 8,00 & & \\
\hline $18 / 04 / 2007$ & & 3,542 & 2,284 & $23 / 11 / 2008$ & 92,00 & & \\
\hline $19 / 04 / 2007$ & & 3,907 & 2,182 & $24 / 11 / 2008$ & 19,00 & & \\
\hline $20 / 04 / 2007$ & & 3,921 & 2,160 & $25 / 11 / 2008$ & 40,50 & & \\
\hline $24 / 04 / 2007$ & & 3,765 & 2,006 & $28 / 11 / 2008$ & & 2,842 & 0,517 \\
\hline $25 / 04 / 2007$ & & 3,599 & 2,030 & $10 / 12 / 2008$ & & 2,475 & 0,504 \\
\hline $26 / 04 / 2007$ & & 3,777 & 2,034 & $12 / 12 / 2008$ & 4,50 & & \\
\hline $27 / 04 / 2007$ & & 3,832 & 2,029 & $14 / 12 / 2008$ & 4,00 & & \\
\hline $30 / 04 / 2007$ & & 3,759 & 1,921 & $19 / 12 / 2008$ & 3,00 & & \\
\hline $02 / 05 / 2007$ & & 3,556 & 1,877 & $20 / 12 / 2008$ & 9,50 & & \\
\hline $04 / 05 / 2007$ & & 3,641 & 1,809 & $21 / 12 / 2008$ & 6,00 & & \\
\hline $07 / 05 / 2007$ & & 3,561 & 1,747 & $22 / 12 / 2008$ & 6,50 & & \\
\hline $08 / 05 / 2007$ & & 3,707 & 1,768 & $23 / 12 / 2008$ & 89,50 & 2,387 & 0,818 \\
\hline 09/05/2007 & & 3,526 & 1,739 & $24 / 12 / 2008$ & 11,50 & & \\
\hline $10 / 05 / 2007$ & & 3,494 & 1,699 & $27 / 12 / 2008$ & 38,50 & & \\
\hline $11 / 05 / 2007$ & & 3,456 & 1,660 & $28 / 12 / 2008$ & 63,00 & & \\
\hline $14 / 05 / 2007$ & & 3,439 & 1,597 & $29 / 12 / 2008$ & 1,50 & & \\
\hline $15 / 05 / 2007$ & & 3,379 & 1,564 & $03 / 01 / 2009$ & 37,50 & & \\
\hline $16 / 05 / 2007$ & & 3,408 & 1,578 & $04 / 01 / 2009$ & 38,00 & & \\
\hline $17 / 05 / 2007$ & & 3,389 & 1,582 & $05 / 01 / 2009$ & 12,00 & & \\
\hline $18 / 05 / 2007$ & & 3,355 & 1,588 & $06 / 01 / 2009$ & 5,00 & & \\
\hline $19 / 05 / 2007$ & 22,00 & 3,409 & 1,642 & $07 / 01 / 2009$ & 10,00 & 5,349 & 2,816 \\
\hline $20 / 05 / 2007$ & 1,50 & & & $11 / 01 / 2009$ & 5,00 & & \\
\hline $21 / 05 / 2007$ & & 3,379 & 1,537 & $14 / 01 / 2009$ & & 4,682 & 4,205 \\
\hline $22 / 05 / 2007$ & 1,70 & 3,357 & 1,519 & $16 / 01 / 2009$ & 1,00 & & \\
\hline $23 / 05 / 2007$ & 11,00 & 3,335 & 1,500 & $18 / 01 / 2009$ & 20,00 & & \\
\hline
\end{tabular}




\begin{tabular}{|c|c|c|c|c|c|c|c|}
\hline $24 / 05 / 2007$ & 1,50 & 3,401 & 1,488 & $23 / 01 / 2009$ & 24,70 & & \\
\hline $25 / 05 / 2007$ & 7,50 & 3,338 & 1,474 & $24 / 01 / 2009$ & 21,00 & & \\
\hline $27 / 05 / 2007$ & 3,40 & & & $25 / 01 / 2009$ & 43,00 & & \\
\hline $28 / 05 / 2007$ & 4,50 & & & $26 / 01 / 2009$ & 34,50 & & \\
\hline $29 / 05 / 2007$ & & 3,276 & 1,416 & $28 / 01 / 2009$ & 10,00 & & \\
\hline $30 / 05 / 2007$ & & 3,307 & 1,475 & $29 / 01 / 2009$ & 25,00 & & \\
\hline $31 / 05 / 2007$ & & 3,267 & 1,417 & $30 / 01 / 2009$ & 8,6 & 5,304 & 7,302 \\
\hline $01 / 06 / 2007$ & & 3,233 & 1,412 & $07 / 02 / 2009$ & 16,00 & & \\
\hline $05 / 06 / 2007$ & 2,50 & 3,199 & 1,325 & $08 / 02 / 2009$ & 7,00 & & \\
\hline $06 / 06 / 2007$ & 1,50 & 3,250 & 1,320 & $10 / 02 / 2009$ & 11,00 & 5,337 & 6,995 \\
\hline $08 / 06 / 2007$ & & 3,253 & 1,318 & $11 / 02 / 2009$ & 14,00 & & \\
\hline $13 / 06 / 2007$ & & 3,166 & 1,270 & $12 / 02 / 2009$ & 32,00 & & \\
\hline $14 / 06 / 2007$ & & 3,169 & 1,257 & $13 / 02 / 2009$ & 7,00 & & \\
\hline $15 / 06 / 2007$ & & 3,148 & 1,257 & $16 / 02 / 2009$ & 9,00 & & \\
\hline $18 / 06 / 2007$ & & 3,150 & 1,230 & $18 / 02 / 2009$ & 5,00 & 5,503 & 7,430 \\
\hline $19 / 06 / 2007$ & & 3,109 & 1,199 & $19 / 02 / 2009$ & 6,50 & & \\
\hline $21 / 06 / 2007$ & & 3,105 & 1,193 & $21 / 02 / 2009$ & 3,00 & & \\
\hline $22 / 06 / 2007$ & & 3,112 & 1,186 & $24 / 02 / 2009$ & 51,00 & & \\
\hline $26 / 06 / 2007$ & & 3,015 & 1,172 & $25 / 02 / 2009$ & 13,00 & & \\
\hline $27 / 06 / 2007$ & & 3,078 & 1,158 & $26 / 02 / 2009$ & 3,50 & & \\
\hline $28 / 06 / 2007$ & & 3,043 & 1,105 & $01 / 03 / 2009$ & 6,5 & 5,613 & 9,091 \\
\hline $02 / 07 / 2007$ & & 3,030 & 1,091 & $08 / 03 / 2009$ & 12,00 & & \\
\hline $03 / 07 / 2007$ & & 3,023 & 1,058 & $09 / 03 / 2009$ & 3,00 & & \\
\hline $06 / 07 / 2007$ & & 3,003 & 1,038 & $13 / 03 / 2009$ & 14,00 & 5,586 & 8,750 \\
\hline 09/07/2007 & & 2,940 & 1,048 & $21 / 03 / 2009$ & 3,00 & & \\
\hline $11 / 07 / 2007$ & & 2,927 & 1,048 & $23 / 03 / 2009$ & 2,00 & & \\
\hline $12 / 07 / 2007$ & & 2,928 & 1,026 & $24 / 03 / 2009$ & & 5,500 & 5,394 \\
\hline $13 / 07 / 2007$ & & 2,908 & 1,039 & $27 / 03 / 2009$ & 12,00 & & \\
\hline $17 / 07 / 2007$ & & 2,856 & 0,976 & $05 / 04 / 2009$ & 24,00 & & \\
\hline $20 / 07 / 2007$ & & 2,836 & 0,940 & $06 / 04 / 2009$ & 11,00 & 5,355 & 4,328 \\
\hline $23 / 07 / 2007$ & & 2,871 & 0,938 & $07 / 04 / 2009$ & 7,00 & & \\
\hline $24 / 07 / 2007$ & & 2,842 & 0,945 & $08 / 04 / 2009$ & 10,00 & & \\
\hline $25 / 07 / 2007$ & & 2,837 & 0,923 & $20 / 04 / 2009$ & 0,80 & & \\
\hline $26 / 07 / 2007$ & & 2,821 & 0,918 & $22 / 04 / 2009$ & 4,60 & & \\
\hline $30 / 07 / 2007$ & & 2,788 & 0,885 & $23 / 04 / 2009$ & 0,20 & 5,419 & 3,458 \\
\hline $31 / 07 / 2007$ & & 2,796 & 0,887 & $04 / 05 / 2009$ & 21,10 & & \\
\hline $01 / 08 / 2007$ & & 2,777 & 0,930 & $07 / 05 / 2009$ & & 5,238 & 2,833 \\
\hline $07 / 08 / 2007$ & & 2,720 & 0,870 & $14 / 05 / 2009$ & & 5,247 & 2,601 \\
\hline $08 / 08 / 2007$ & & 2,747 & 0,868 & $18 / 05 / 2009$ & 9,10 & & \\
\hline $27 / 08 / 2007$ & & 2,601 & 0,000 & $21 / 05 / 2009$ & & 5,381 & 2,453 \\
\hline $29 / 08 / 2007$ & & 2,509 & 0,781 & $29 / 05 / 2009$ & & 5,289 & 2,132 \\
\hline $31 / 08 / 2007$ & & 2,515 & 0,697 & $12 / 06 / 2009$ & & 5,249 & 1,817 \\
\hline $04 / 09 / 2007$ & & 2,521 & 0,699 & $17 / 06 / 2009$ & & 5,066 & 1,680 \\
\hline $05 / 09 / 2007$ & & 2,489 & 0,706 & $20 / 06 / 2009$ & & 5,048 & 1,647 \\
\hline 06/09/2007 & & 2,486 & 0,717 & $25 / 06 / 2009$ & & 5,057 & 1,520 \\
\hline $10 / 09 / 2007$ & & 2,435 & 0,703 & $02 / 07 / 2009$ & & 5,063 & 1,514 \\
\hline $13 / 09 / 2007$ & & 2,435 & 0,703 & $07 / 07 / 2009$ & & 5,012 & 1,412 \\
\hline $17 / 09 / 2007$ & & 2,399 & 0,705 & $15 / 07 / 2009$ & & 4,963 & 1,327 \\
\hline $20 / 09 / 2007$ & & 2,378 & 0,698 & $31 / 07 / 2009$ & & 5,059 & 1,198 \\
\hline $21 / 09 / 2007$ & & 2,424 & 0,712 & $05 / 08 / 2009$ & & 4,888 & 1,067 \\
\hline $25 / 09 / 2007$ & & 2,370 & 0,696 & $14 / 08 / 2009$ & & 4,850 & 1,049 \\
\hline $27 / 09 / 2007$ & & 2,350 & 0,690 & $02 / 09 / 2009$ & & 4,736 & 0,937 \\
\hline $28 / 09 / 2007$ & & 2,367 & 0,695 & $08 / 09 / 2009$ & 2,10 & & \\
\hline $02 / 10 / 2007$ & & 2,328 & 0,684 & $10 / 09 / 2009$ & 10,20 & & \\
\hline
\end{tabular}




\begin{tabular}{|c|c|c|c|c|c|c|c|}
\hline $03 / 10 / 2007$ & & 2,330 & 0,684 & $11 / 09 / 2009$ & 50,40 & & \\
\hline $08 / 10 / 2007$ & & 2,291 & 0,673 & $14 / 09 / 2009$ & 0,30 & & \\
\hline $10 / 10 / 2007$ & & 2,296 & 0,674 & $18 / 09 / 2009$ & & 4,705 & 0,865 \\
\hline $11 / 10 / 2007$ & & 2,287 & 0,672 & $25 / 09 / 2009$ & 0,50 & & \\
\hline $14 / 10 / 2007$ & 1,00 & 2,259 & 0,631 & $05 / 10 / 2009$ & 15,30 & 5,225 & 0,857 \\
\hline $15 / 10 / 2007$ & 31,00 & 2,232 & 0,589 & $14 / 10 / 2009$ & 14,60 & & \\
\hline $16 / 10 / 2007$ & 3,00 & 2,239 & 0,600 & $17 / 10 / 2009$ & 0,80 & & \\
\hline $18 / 10 / 2007$ & & 2,247 & 0,629 & $18 / 10 / 2009$ & 0,30 & & \\
\hline $21 / 10 / 2007$ & 30,00 & & & $20 / 10 / 2009$ & & 4,503 & 0,763 \\
\hline $22 / 10 / 2007$ & 47,00 & 2,227 & 0,613 & $28 / 10 / 2009$ & 0,20 & & \\
\hline $23 / 10 / 2007$ & 43,00 & 2,272 & 0,671 & $29 / 10 / 2009$ & 0,30 & & \\
\hline $24 / 10 / 2007$ & 23,00 & 2,359 & 0,681 & $30 / 10 / 2009$ & 20,30 & 4,854 & 0,801 \\
\hline $25 / 10 / 2007$ & 1,50 & 2,445 & 0,692 & $31 / 10 / 2009$ & 2,70 & & \\
\hline $26 / 10 / 2007$ & & 2,491 & 0,643 & $01 / 11 / 2009$ & 2,40 & & \\
\hline $29 / 10 / 2007$ & & 2,665 & 0,593 & $02 / 11 / 2009$ & 5,60 & & \\
\hline $30 / 10 / 2007$ & & 2,672 & 0,593 & $03 / 11 / 2009$ & 37,40 & & \\
\hline $01 / 11 / 2007$ & & 2,652 & 0,613 & $04 / 11 / 2009$ & 13,80 & & \\
\hline $05 / 11 / 2007$ & & 2,572 & 0,625 & $08 / 11 / 2009$ & 18,50 & & \\
\hline $06 / 11 / 2007$ & 11,00 & 2,529 & 0,615 & $09 / 11 / 2009$ & & 4,700 & 0,902 \\
\hline $08 / 11 / 2007$ & 7,50 & & & $11 / 11 / 2009$ & 16,30 & & \\
\hline $09 / 11 / 2007$ & 1,70 & & & $12 / 11 / 2009$ & 5,00 & 4,793 & 1,039 \\
\hline $10 / 11 / 2007$ & 15,00 & 2,442 & 0,633 & $20 / 11 / 2009$ & & 4,781 & 1,245 \\
\hline $11 / 11 / 2007$ & 2,00 & & & $01 / 12 / 2009$ & & 4,125 & 1,097 \\
\hline $12 / 11 / 2007$ & & 2,354 & 0,651 & $02 / 12 / 2009$ & 34,50 & & \\
\hline $13 / 11 / 2007$ & 13,00 & 2,348 & 0,650 & $03 / 12 / 2009$ & 18,10 & & \\
\hline $14 / 11 / 2007$ & 8,30 & 2,318 & 0,665 & $04 / 12 / 2009$ & 1,40 & & \\
\hline $15 / 11 / 2007$ & 5,00 & & & $05 / 12 / 2009$ & 29,10 & & \\
\hline $16 / 11 / 2007$ & & 2,312 & 0,698 & $06 / 12 / 2009$ & 8,80 & & \\
\hline $18 / 11 / 2007$ & 7,00 & & & 09/12/2009 & 2,10 & & \\
\hline $19 / 11 / 2007$ & 7,00 & 2,339 & 0,706 & $10 / 12 / 2009$ & 15,20 & & \\
\hline $20 / 11 / 2007$ & 3,00 & 2,365 & 0,679 & $11 / 12 / 2009$ & 23,30 & & \\
\hline $21 / 11 / 2007$ & 1,50 & 2,362 & 0,678 & $12 / 12 / 2009$ & 32,50 & & \\
\hline $23 / 11 / 2007$ & & 2,393 & 0,663 & $14 / 12 / 2009$ & & 5,355 & 1,790 \\
\hline $27 / 11 / 2007$ & & 2,402 & 0,633 & $15 / 12 / 2009$ & 0,60 & & \\
\hline $28 / 11 / 2007$ & & 2,402 & 0,633 & $16 / 12 / 2009$ & 14,70 & & \\
\hline $30 / 11 / 2007$ & & 2,413 & 0,653 & $17 / 12 / 2009$ & 4,00 & & \\
\hline $01 / 12 / 2007$ & 2,50 & & & $18 / 12 / 2009$ & 36,50 & & \\
\hline $03 / 12 / 2007$ & & 2,402 & 0,705 & $19 / 12 / 2009$ & 0,80 & & \\
\hline $04 / 12 / 2007$ & 1,70 & 2,415 & 0,709 & $20 / 12 / 2009$ & 4,00 & & \\
\hline $05 / 12 / 2007$ & 8,20 & 2,409 & 0,771 & $27 / 12 / 2009$ & & 4,865 & 2,779 \\
\hline $06 / 12 / 2007$ & 6,50 & 2,402 & 0,834 & $10 / 01 / 2010$ & 1,00 & & \\
\hline $07 / 12 / 2007$ & & 2,422 & 0,778 & $11 / 01 / 2010$ & 1,40 & & \\
\hline 09/12/2007 & 4,00 & 2,699 & 1,010 & $12 / 01 / 2010$ & 25,30 & & \\
\hline $10 / 12 / 2007$ & 37,30 & & & $13 / 01 / 2010$ & 3,00 & & \\
\hline $11 / 12 / 2007$ & 70,50 & 2,975 & 1,243 & $14 / 01 / 2010$ & 51,30 & & \\
\hline $12 / 12 / 2007$ & 34,00 & 3,584 & 1,355 & $16 / 01 / 2010$ & 8,80 & & \\
\hline $13 / 12 / 2007$ & 9,00 & 4,194 & 1,468 & $17 / 01 / 2010$ & 23,20 & & \\
\hline $14 / 12 / 2007$ & 2,50 & 4,860 & 1,480 & $18 / 01 / 2010$ & 9,40 & & \\
\hline $15 / 12 / 2007$ & 1,50 & & & $19 / 01 / 2010$ & & 4,884 & 3,538 \\
\hline $17 / 12 / 2007$ & 1,00 & 5,323 & 2,864 & $20 / 01 / 2010$ & 3,20 & & \\
\hline $18 / 12 / 2007$ & & 5,105 & 3,265 & $21 / 01 / 2010$ & 20,30 & & \\
\hline $19 / 12 / 2007$ & & 4,886 & 3,666 & $22 / 01 / 2010$ & 60,10 & & \\
\hline $20 / 12 / 2007$ & & 4,711 & 3,598 & $29 / 01 / 2010$ & 2,60 & & \\
\hline $21 / 12 / 2007$ & & 4,535 & 3,530 & $01 / 02 / 2010$ & 1,90 & & \\
\hline
\end{tabular}




\begin{tabular}{|c|c|c|c|c|c|c|c|}
\hline $27 / 12 / 2007$ & & 3,469 & 2,807 & $02 / 02 / 2010$ & 0,50 & 4,844 & 3,508 \\
\hline $28 / 12 / 2007$ & & 3,362 & 2,734 & $03 / 02 / 2010$ & 0,30 & & \\
\hline $29 / 12 / 2007$ & & & & $06 / 02 / 2010$ & 1,90 & & \\
\hline $30 / 12 / 2007$ & & & & $07 / 02 / 2010$ & 31,00 & & \\
\hline $31 / 12 / 2007$ & & & & $08 / 02 / 2010$ & 17,00 & & \\
\hline $01 / 01 / 2008$ & 14,50 & & & $11 / 02 / 2010$ & 1,40 & & \\
\hline $02 / 01 / 2008$ & & 2,949 & 2,413 & $14 / 02 / 2010$ & & 4,852 & 3,752 \\
\hline $03 / 01 / 2008$ & & 2,884 & 2,392 & $20 / 02 / 2010$ & 12,80 & & \\
\hline $07 / 01 / 2008$ & & 2,698 & 2,229 & $21 / 02 / 2010$ & 8,50 & & \\
\hline $08 / 01 / 2008$ & & 2,640 & 2,182 & $02 / 03 / 2010$ & & 4,864 & 4,108 \\
\hline $09 / 01 / 2008$ & 1,00 & 2,630 & 2,156 & $14 / 03 / 2010$ & 0,30 & 4,701 & 4,396 \\
\hline $10 / 01 / 2008$ & & 2,641 & 2,113 & $17 / 03 / 2010$ & 2,10 & & \\
\hline $14 / 01 / 2008$ & 3,00 & & & $18 / 03 / 2010$ & 2,20 & & \\
\hline $15 / 01 / 2008$ & 16,00 & 2,486 & 1,979 & $25 / 03 / 2010$ & 0,20 & & \\
\hline $21 / 01 / 2008$ & & 2,370 & 1,844 & $11 / 04 / 2010$ & 0,30 & & \\
\hline $22 / 01 / 2008$ & & 2,348 & 1,822 & $21 / 04 / 2010$ & 0,50 & & \\
\hline $23 / 01 / 2008$ & & 2,345 & 1,821 & $22 / 04 / 2010$ & 6,40 & & \\
\hline $24 / 01 / 2008$ & 23,50 & 2,343 & 1,820 & $25 / 04 / 2010$ & 0,30 & & \\
\hline $25 / 01 / 2008$ & 38,50 & 2,372 & 1,852 & $01 / 06 / 2010$ & 0,20 & & \\
\hline $29 / 01 / 2008$ & & 2,432 & 1,899 & $10 / 06 / 2010$ & 11,50 & & \\
\hline $30 / 01 / 2008$ & 28,00 & 2,493 & 1,946 & $13 / 06 / 2010$ & 0,30 & & \\
\hline $01 / 02 / 2008$ & & 2,597 & 1,973 & $14 / 06 / 2010$ & 12,80 & & \\
\hline $04 / 02 / 2008$ & & 2,731 & 2,143 & $16 / 06 / 2010$ & 1,90 & & \\
\hline $07 / 02 / 2008$ & 5,50 & 2,724 & 2,253 & $17 / 06 / 2010$ & 9,00 & & \\
\hline $08 / 02 / 2008$ & 8,00 & 2,842 & 2,461 & $19 / 06 / 2010$ & 10,70 & & \\
\hline $09 / 02 / 2008$ & 45,00 & 2,960 & 2,669 & $21 / 06 / 2010$ & 0,80 & & \\
\hline $10 / 02 / 2008$ & 13,00 & 3,077 & 2,878 & $26 / 06 / 2010$ & 16,80 & & \\
\hline $11 / 02 / 2008$ & 44,00 & 3,195 & 3,086 & $27 / 06 / 2010$ & 11,00 & & \\
\hline $12 / 02 / 2008$ & 0,50 & 3,676 & 3,300 & $28 / 06 / 2010$ & 9,60 & 4,212 & 0,719 \\
\hline $13 / 02 / 2008$ & & 4,213 & 3,593 & $02 / 07 / 2010$ & 0,30 & & \\
\hline $14 / 02 / 2008$ & & 4,520 & 4,542 & $12 / 07 / 2010$ & 32,90 & 4,480 & 1,694 \\
\hline $17 / 02 / 2008$ & 17,50 & 4,7 & 5,772 & $13 / 07 / 2010$ & 7,70 & & \\
\hline $20 / 02 / 2008$ & 13,00 & 4,880 & 7,001 & $15 / 07 / 2010$ & 8,00 & & \\
\hline $25 / 02 / 2008$ & & 5,453 & 9,912 & $17 / 07 / 2010$ & 0,30 & & \\
\hline $26 / 02 / 2008$ & & 5,559 & 9,925 & $19 / 07 / 2010$ & & 4,978 & 3,799 \\
\hline $27 / 02 / 2008$ & & 5,664 & 9,937 & $24 / 07 / 2010$ & 0,50 & & \\
\hline $03 / 03 / 2008$ & & 5,483 & 7,712 & $25 / 07 / 2010$ & 10,70 & & \\
\hline $04 / 03 / 2008$ & & 5,614 & 7,358 & $09 / 08 / 2010$ & 5,00 & & \\
\hline $05 / 03 / 2008$ & & 5,486 & 7,106 & $10 / 08 / 2010$ & 10,00 & & \\
\hline $12 / 03 / 2008$ & 14,50 & & & $11 / 08 / 2010$ & 30,00 & & \\
\hline $13 / 03 / 2008$ & & 5,192 & 5,085 & $13 / 08 / 2010$ & 8,70 & & \\
\hline $15 / 03 / 2008$ & & 5,104 & 4,765 & $15 / 08 / 2010$ & 41,90 & 4,626 & 1,100 \\
\hline $17 / 03 / 2008$ & & 5,097 & 4,481 & $16 / 08 / 2010$ & 14,50 & & \\
\hline $18 / 03 / 2008$ & & 4,955 & 4,293 & $02 / 10 / 2010$ & 0,20 & & \\
\hline $20 / 03 / 2008$ & & 5,075 & 4,104 & $11 / 10 / 2010$ & 11,50 & & \\
\hline $22 / 03 / 2008$ & & 4,988 & 3,942 & $14 / 10 / 2010$ & 0,30 & & \\
\hline $24 / 03 / 2008$ & & 4,901 & 3,779 & $15 / 10 / 2010$ & 12,80 & & \\
\hline $27 / 03 / 2008$ & & 4,381 & 3,231 & $17 / 10 / 2010$ & 1,90 & & \\
\hline $28 / 03 / 2008$ & 5,50 & & & $18 / 10 / 2010$ & 9,00 & & \\
\hline $29 / 03 / 2008$ & 1,50 & 4,617 & 3,333 & $20 / 10 / 2010$ & 10,70 & & \\
\hline $30 / 03 / 2008$ & 7,00 & & & $22 / 10 / 2010$ & 0,80 & & \\
\hline $31 / 03 / 2008$ & & 4,853 & 3,435 & $27 / 10 / 2010$ & 16,80 & & \\
\hline $02 / 04 / 2008$ & & 4,848 & 3,303 & $28 / 10 / 2010$ & 11,00 & & \\
\hline $03 / 04 / 2008$ & 32,50 & & & $29 / 10 / 2010$ & 9,60 & 4,212 & 0,719 \\
\hline
\end{tabular}




\begin{tabular}{l|l|l|l|l|l|l|l}
$04 / 04 / 2008$ & 6,00 & 4,843 & 3,170 & $02 / 11 / 2010$ & 0,30 & & \\
\hline $05 / 04 / 2008$ & 12,50 & & & $12 / 11 / 2010$ & 32,90 & 4,480 & 1,694 \\
\hline $07 / 04 / 2008$ & & 4,886 & 3,120 & $13 / 11 / 2010$ & 7,70 & & \\
\hline $09 / 04 / 2008$ & & 4,940 & 3,056 & $15 / 11 / 2010$ & 8,00 & & \\
\hline $11 / 04 / 2008$ & & 4,403 & 2,031 & $17 / 11 / 2010$ & 0,30 & & \\
\hline $13 / 04 / 2008$ & & 4,626 & 2,425 & $19 / 11 / 2010$ & & 4,978 & 3,799 \\
\hline $15 / 04 / 2008$ & & 4,849 & 2,819 & $24 / 11 / 2010$ & 0,50 & & \\
\hline $16 / 04 / 2008$ & & 4,884 & 2,737 & $25 / 11 / 2010$ & 10,70 & & \\
\hline $18 / 04 / 2008$ & & 4,769 & 2,450 & $10 / 12 / 2010$ & 5,00 & & \\
\hline $23 / 04 / 2008$ & & 4,654 & 2,418 & $11 / 12 / 2010$ & 10,00 & & \\
\hline $27 / 04 / 2008$ & 6,00 & & & $12 / 12 / 2010$ & 30,00 & & \\
\hline $28 / 04 / 2008$ & 10,00 & & & $14 / 12 / 2010$ & 8,70 & & \\
\hline $29 / 04 / 2008$ & & 4,670 & 2,248 & $16 / 12 / 2010$ & 41,90 & 4,626 & 1,100 \\
\hline $30 / 04 / 2008$ & & 4,690 & 2,086 & & & &
\end{tabular}

